Article

\title{
Joining Aluminium Alloy 5A06 to Stainless Steel 321 by Vaporizing Foil Actuators Welding with an Interlayer
}

\author{
Shan Su ${ }^{1}$, Shujun Chen ${ }^{1, *}$, Yu Mao ${ }^{2}$, Jun Xiao ${ }^{1}$, Anupam Vivek ${ }^{2}$ and Glenn Daehn ${ }^{2}$ (i) \\ 1 College of Mechanical Engineering and Applied Electronics Technology, Beijing University of Technology, \\ 100 Ping Le Yuan, Beijing 100124, China; sushans@foxmail.com (S.S.); jun.xiao@bjut.edu.cn (J.X.) \\ 2 Department of Materials Science and Engineering, The Ohio State University, 2041, College Road, Columbus, \\ OH 43221, USA; mao.154@osu.edu (Y.M.); vivek.4@osu.edu (A.V.); daehn.1@osu.edu (G.D.) \\ * Correspondence: sjchen@bjut.edu.cn; Tel.: +86-010-67391620
}

Received: 27 November 2018; Accepted: 29 December 2018; Published: 5 January 2019

\begin{abstract}
Direct aluminium-stainless steel joints are difficult to create by the vaporized foil actuator welding (VFAW) method because brittle intermetallic compounds (IMCs) tend to form along the interface. The use of an interlayer as a transition layer between the two materials with vast difference in hardness and ductility was proposed as a solution to reduce the formation of the IMCs. In this work, VFAW was used to successfully weld sheet aluminium alloy 5A06 to stainless steel 321 with a 3003 aluminium alloy interlayer. Input energy levels of $6 \mathrm{~kJ}, 8 \mathrm{~kJ}, 10 \mathrm{~kJ}$, and $12 \mathrm{~kJ}$ were used and as a trend, higher energy inputs resulted in higher impact velocities, larger weld area, and better mechanical properties. In lap-shear and peel testing, all samples failed at the interface of the interlayer and target. At $10 \mathrm{~kJ}$ energy input, flyer velocities up to $935 \mathrm{~m} / \mathrm{s}$, lap-shear peak load of $44 \mathrm{kN}$, and peel load of $2.15 \mathrm{kN}$ were achieved. Microstructure characterization and element distribution were performed, and the results show a wavy pattern created between the flyer and interlayer which have similar properties, and the interface between the interlayer and target was dominated by element diffusion and IMCs identified mainly as $\mathrm{FeAl}_{3}$ and FeAl. The results demonstrate VFAW is a suitable joining method for dissimilar metals such as aluminium alloy and stainless steel, which has a broad and significant application prospect in aerospace and chemical industry.
\end{abstract}

Keywords: dissimilar materials; interlayer; vaporizing foil actuators welding

\section{Introduction}

Aluminium-stainless steel sheet joints are of great interest for purposes of lightweighting and corrosion protection in industry applications [1]. Aluminium can be joined with stainless steel via adhesive bonding or mechanical fastening [2]. However, in order to weld aluminium to stainless steel, special techniques are required. Dissimilar metals fusion welding processes have many difficulties as a result of metallurgical incompatibility [3], the formation of brittle phases, the segregation of highand low-melting phases due to chemical mismatch, and possibly large residual stresses from the physical mismatch. Fusion-based welding techniques such as resistance spot welding [4] (RSW) and arc and laser welding-brazing [5-8] are most common in aluminium-stainless steel welding. The joints welded through the fusion-based welding process produce brittle intermetallic compound (IMC), which easily leads to fracture due to different physical and chemical properties between dissimilar metals. Solid state welding is a suitable welding method for joining dissimilar metals and can overcome some of the disadvantages associated with the fusion-based welding process [9]. Several solid state welding methods, including explosion welding [10-15] (EXW), ultrasonic welding [16], magnetic 
pulse welding [17,18] (MPW), and friction stir welding [1,19,20] (FSW), have been used to weld the dissimilar materials such as aluminium alloy and stainless steel. EXW and MPW are variants of impact or collision welding, which has been established as a fast and reliable technology [15]. MPW is applied for the weld length of centimeters, while EXW is more suitable for meters. Corigliano et al. [10,11] investigated the static and fatigue bending tests of explosive welded joints of ASTM A516 low carbon steel and A5086 aluminium alloy with pure aluminium as an interlayer. Han et al. [21] use AA1050 plate as interlayer in EXW of AA5083 aluminium alloy plate and SS41 steel plate. The thin interlayer enhanced the bond strength and suppressed the formation of the brittle interfacial zone and the thickness of the generated interfacial zone increased as the thickness of the interlayer increased from $0.5 \mathrm{~mm}$ to $2 \mathrm{~mm}$. Manikandan et al. [22] employed different thickness of interlayer to analyze the energetic conditions of the titanium/304 stainless steel joints welded by explosive welding process. The results show that a thin interlayer leads to successful welding as the use of interlayer splits the kinetic energy deposition between the two interfaces and thereby reduces the possibility of melting or formation of IMCs.

Vaporizing foil actuator welding (VFAW) is a novel solid state welding technology making use of the impulse created by vaporization of the metallic foil or wire by the passage of a high current [23]. The high-amplitude impulse accelerates the flyer workpiece toward the target workpiece. The high velocity oblique impact spits out the surface contaminants in the form of a jet and the high pressure metal-to-metal contact leads to formation of metallic bonds [24]. The technology proves to be robust to join several dissimilar metals such as $\mathrm{Al}-\mathrm{Mg}, \mathrm{Al}-\mathrm{Cu}, \mathrm{Al}-\mathrm{Fe}, \mathrm{Al}-\mathrm{Ti}$, etc. [25-28]. However, further development and understanding of the process is needed in order to accomplish industrial adoption. There are also certain pairs which cannot be joined directly with this process. In such cases, an interlayer can prove to be useful.

In this study, 3003 aluminium alloy was chosen as the interlayer in the 5A06 aluminium alloy and 321 stainless steel VFAW welding process. This research further studied the effects of the interlayer on the microstructure and mechanical properties of the welds. Welded joints were evaluated based on mechanical strength and microstructure. The characteristics of mechanical interlocking and metallurgical bonding areas were studied by advanced microscopy.

\section{Experimental Procedure}

\subsection{Materials and Methods}

This work follows the VFAW method described by Vivek et al. [23]. The flyer sheet was placed directly against an aluminium foil which was insulated by a $0.12 \mathrm{~mm}$ thick polyimide (trade name Kapton) tape and the ends of steel terminals were connected to a capacitor bank. The characteristics of the capacitor bank are shown in Table 1.

Table 1. Capacitor bank characteristics.

\begin{tabular}{ccccc}
\hline Capacitance & Inductance & Resistance & Maximum Charging Energy & Short Circuit Current Rise Time \\
\hline $426 \mu \mathrm{F}$ & $100 \mathrm{nH}$ & $10 \mathrm{~m} \Omega$ & $16 \mathrm{~kJ}$ at $8.66 \mathrm{kV}$ & $12 \mu \mathrm{s}$ \\
\hline
\end{tabular}

As the capacitor bank was discharged, the foil vaporized in $10 \sim 15 \mu$ s under the current of 100 300 kA. The flyer sheet accelerated to a high velocity $(300 \sim 1200 \mathrm{~m} / \mathrm{s})$ by the forces of the vaporized foil. $0.076 \mathrm{~mm}$ thick aluminium foils were used for energy input lower than $10 \mathrm{~kJ}$, and $0.125 \mathrm{~mm}$ thick foils were used for $12 \mathrm{~kJ}$ energy input. The active area of the foils was $12.7 \mathrm{~mm}$ wide and $50.8 \mathrm{~mm}$ long. A schematic of the apparatus as well as the actual implementation, the sketch of the aluminium foil, and the schematic of VFAW process are shown in Figure 1. Annealed aluminium alloy type 5A06 $(1.8 \times 70 \times 140$, in $\mathrm{mm})$ and $3003(1.02 \times 70 \times 70$, in $\mathrm{mm})$ sheets were chosen as the flyer and interlayer material. 321 stainless steel sheets were cut to $4 \mathrm{~mm} \times 70 \mathrm{~mm} \times 140 \mathrm{~mm}$. The standoff distances between the flyer and interlayer and the interlayer and target were $3 \mathrm{~mm}$ and $1.5 \mathrm{~mm}$, respectively, 
in all experiments. The impacting surfaces of all materials were cleaned prior to welding with acetone after being ground by emery paper.

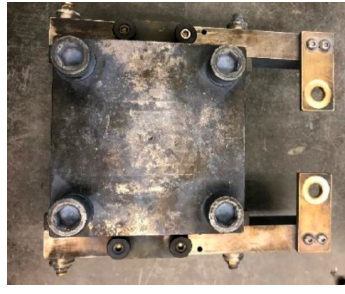

(a)

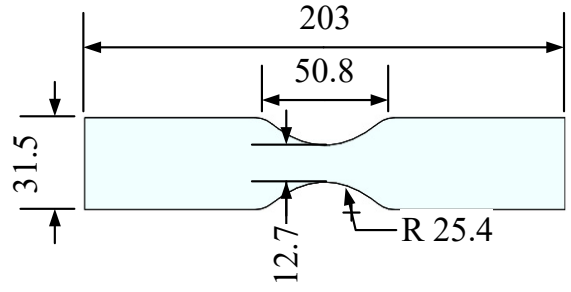

(c)

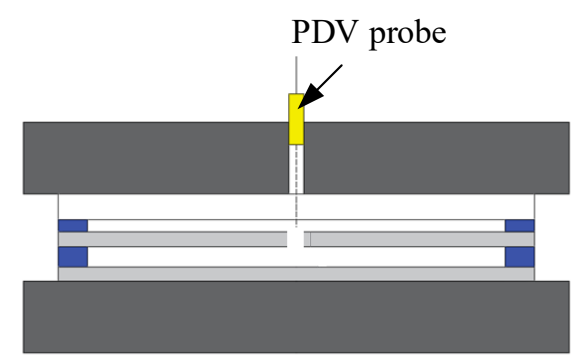

(b)

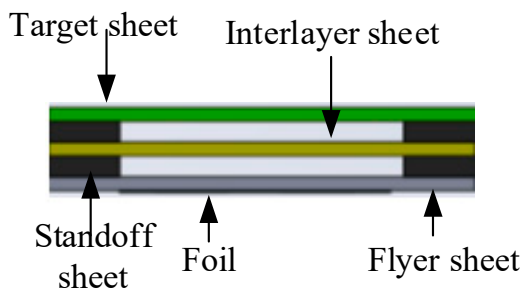

(d)

Figure 1. (a) actual implementation of the vaporizing foil actuator welding (VFAW) apparatus; (b) impact velocity test apparatus; (c) sketch of the aluminium foil; (d) schematic of the VFAW process.

\subsection{Velocity Measurement}

Input energies of $6 \mathrm{~kJ}, 8 \mathrm{~kJ}, 10 \mathrm{~kJ}$, and $12 \mathrm{~kJ}$ were used in this study. Current and voltage of the foil vaporized in VFAW process were measured using a 50 kA:1 V Rogowski coil and 1000:1 high voltage probe, respectively. The velocity of flyer and interlayer impact to the target was recorded using photonic Doppler velocimetry (PDV) [29]. A hole was drilled in the center of the backing steel fixture and the interlayer using transparent acrylic as the replacement of the target sheet to allow the laser focusing probe to look at the interlayer directly. The velocity at any distance within this range can then be estimated by integration of the resulting velocity-time curve.

\subsection{Strength Testing}

Lap-shear and peel tests were used to analyze the joint strength. A schematic of the strength testing is shown in Figure 2. Three samples from each input energy were tested. For peel testing, the flyer sheets were bent to $90^{\circ}$ with respect to the interlayer and target, and the target sheets were fixed to a steel die by a bolt. Testing was carried out using an MTS810 mechanical testing frame at a constant extension rate of $0.1 \mathrm{~mm} / \mathrm{s}$.

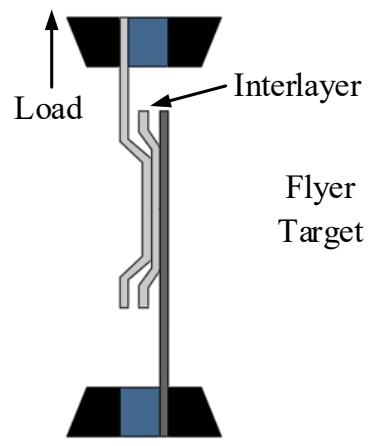

(a)

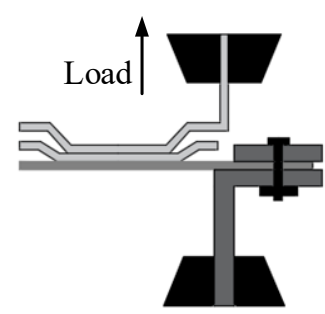

(b)

Figure 2. Mechanical testing schematic. (a) Peel test; (b) Lap-shear test. 
Interfacial morphologies and element content and distribution in the interface of interlayer and target were observed by scanning electron microscopy (SEM) using a Zeiss Ultra55 equipped with a silicon drift detector for energy-dispersive X-ray spectroscopy (EDS). Optical microscopy was used to analyze the interfacial morphologies of the flyer and interlayer.

\section{Results and Discussion}

\subsection{Velocity, Current, and Voltage Traces}

The temporal evolutions of current, voltage, and velocity of the flyer sheet with $8 \mathrm{~kJ}$ energy input in VFAW process are shown in Figure 3.

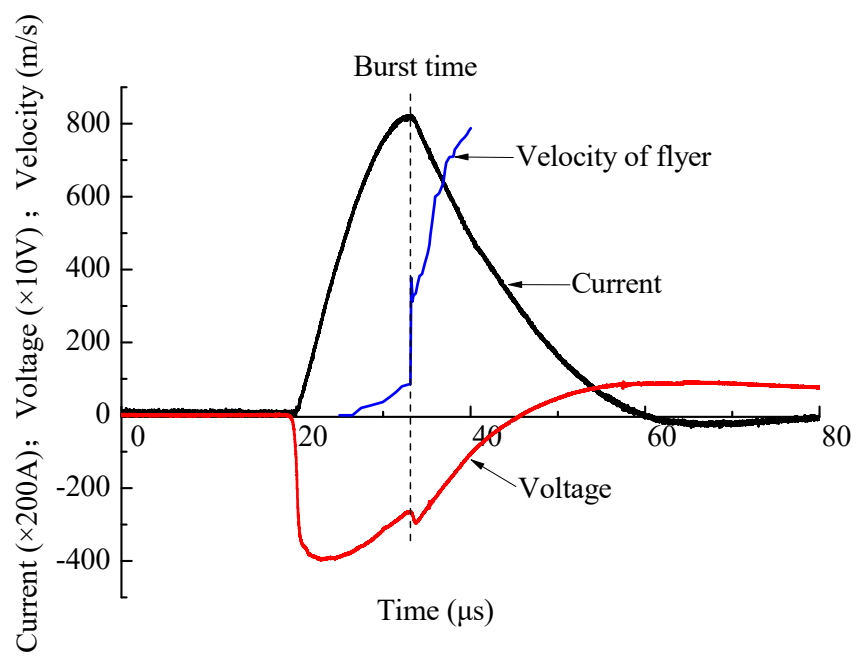

Figure 3. Voltage, current, and velocity traces with $8 \mathrm{~kJ}$ energy input.

The flyer sheet has a low acceleration (from 25 to $33 \mu \mathrm{s}$ ) under the electromagnetic interaction force generated by the current carrying foil [30]. The voltage has a sharp spike rise and a sudden decrease of current, while the flyer sheet accelerated to $393 \mathrm{~m} / \mathrm{s}$ instant at about $33.5 \mu \mathrm{s}$. This moment also called burst time in the VFAW process. This voltage spike rise is a typical phenomenon in foil vaporized process due to the resistance increase when the foil is vaporized and converted into high pressure plasma. The flyer and interlayer sheet impacted at the target sheet at a velocity of $788 \mathrm{~m} / \mathrm{s}$. The velocity trace of flyer sheet with other three energies input are shown in Figure 4. The impact velocities were $635 \mathrm{~m} / \mathrm{s}, 788 \mathrm{~m} /, 935 \mathrm{~m} / \mathrm{s}$, and $1025 \mathrm{~m} / \mathrm{s}$ for input energies of $6 \mathrm{~kJ}, 8 \mathrm{~kJ}, 10 \mathrm{~kJ}$, and $12 \mathrm{~kJ}$, respectively.

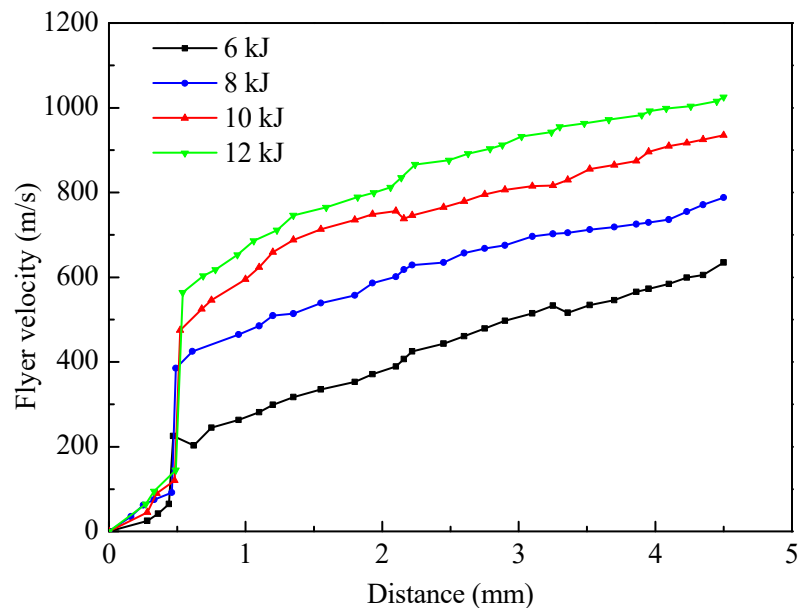

Figure 4. Flyer sheet velocity traces at $6 \mathrm{~kJ}, 8 \mathrm{~kJ}, 10 \mathrm{~kJ}$, and $12 \mathrm{~kJ}$ input energies. 


\subsection{Mechanical Testing}

Mechanical testing results from lap-shear and peel tests are summarized in Table 2. The peak load of lap-shear and peel tests increased with energy input increased from $6 \mathrm{~kJ}$ to $10 \mathrm{~kJ}$. The average lap-shear loads were $29.9 \mathrm{kN}$, and $35 \mathrm{kN}, 44 \mathrm{kN}$, and $42.6 \mathrm{kN}$ for the $6 \mathrm{~kJ}, 8 \mathrm{~kJ}, 10 \mathrm{~kJ}$, and $12 \mathrm{~kJ}$ input energies, respectively. The average peak peel loads were $1.62 \mathrm{kN}, 1.65 \mathrm{kN}, 2.15 \mathrm{kN}$, and $2.03 \mathrm{kN}$, respectively.

Table 2. Lap-shear and peel test results.

\begin{tabular}{ccccccccc}
\hline Energy Input & Lap-Shear Average & Test 1 & Test 2 & Test 3 & Peel Average & Test 1 & Test 2 & Test 3 \\
\hline $\mathbf{( k J )}$ & $\mathbf{( k N )}$ & $\mathbf{( k N )}$ & $\mathbf{( k N )}$ & $\mathbf{( k N )}$ & $\mathbf{( k N )}$ & $\mathbf{( k N )}$ & $\mathbf{( k N )}$ & $\mathbf{( k N )}$ \\
\hline 6 & 29.9 & 28.8 & 31.9 & 28.9 & 1.62 & 1.59 & 1.61 & 1.66 \\
8 & 35 & 34.2 & 36.2 & 34.7 & 1.65 & 1.69 & 1.65 & 1.62 \\
10 & 44 & 43.5 & 45.4 & 43.1 & 2.15 & 2.12 & 2.18 & 2.16 \\
12 & 42.6 & 42.9 & 42.2 & 42.6 & 2.03 & 2.01 & 2.04 & 2.03 \\
\hline
\end{tabular}

The load-displacement curves of the lap-shear samples are shown in Figure 5. The lap-shear test fractured surface are shown in Figure 6. The failure zones of all specimens for lap-shear and peel test are located at the interface between the interlayer and target plate. As shown in the cross-sectional morphology of the specimen for tensile test, the good weld area between the flyer plate and interlayer is smaller than that between the interlayer and target plate. The diameter of the failure zone increases from $16 \mathrm{~mm}$ to $28.8 \mathrm{~mm}$ with the input energy from $6 \mathrm{~kJ}$ to $10 \mathrm{~kJ}$, thereby increasing the peak tensile force sustained by the joint. The results show that the welded area of the flyer and interlayer was smaller than that of interlayer and target, and the bonding strength of interlayer and target near the center is smaller than that of outside. The samples welded at higher energies had larger welding interface of interlayer and flyer, and these correlated with higher bonding strength. However, the increase of the input energy slightly reduced the strength of the joining between the interlayer and target with the failure load decreasing from $44 \mathrm{kN}$ to $42.6 \mathrm{kN}$.

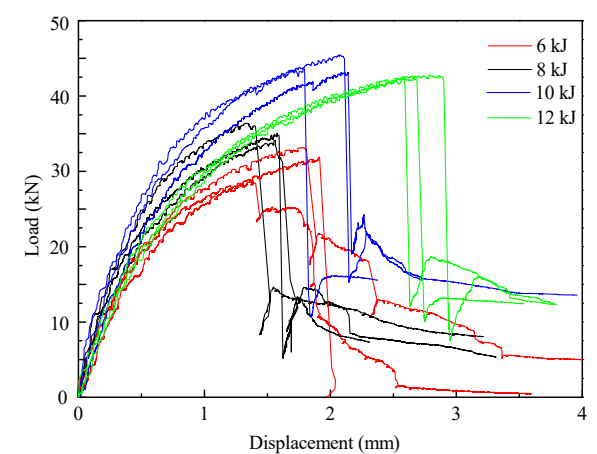

(a)

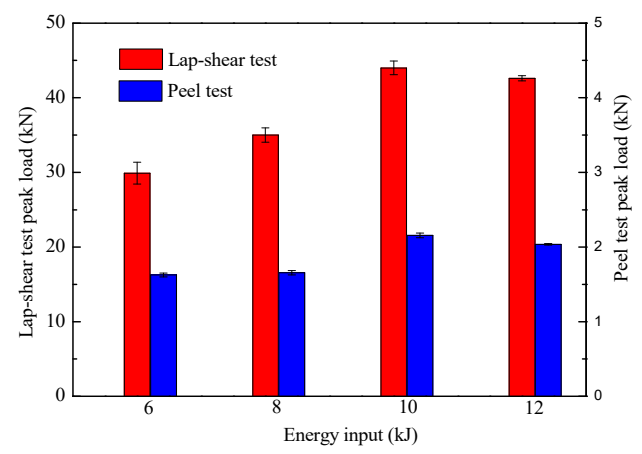

(b)

Figure 5. Lap-shear and peel test results at $6 \mathrm{~kJ}, 8 \mathrm{~kJ}, 10 \mathrm{~kJ}$, and $12 \mathrm{~kJ}$ energies input. (a) Loaddisplacement curves of lap-shear test; (b) Lap-shear and peel average load.

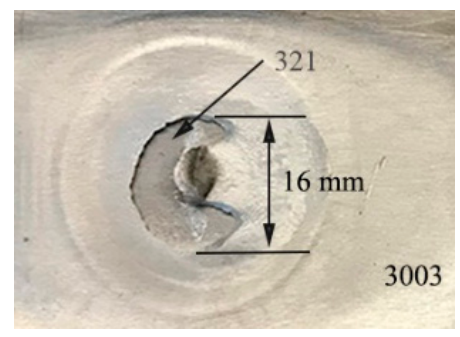

$6 \mathrm{~kJ}$

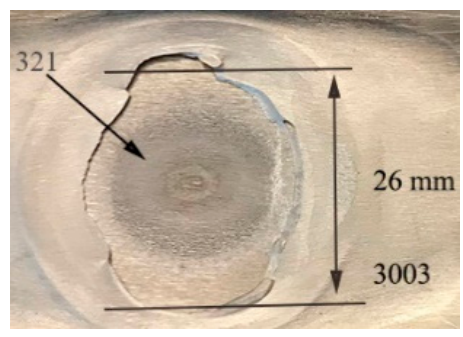

$8 \mathrm{~kJ}$

Figure 6. Cont. 


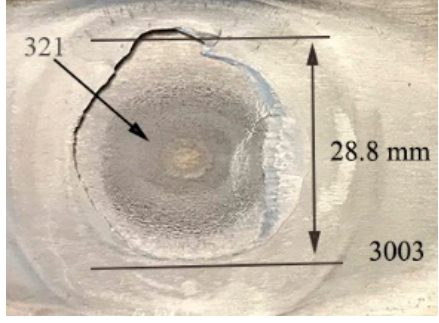

$10 \mathrm{~kJ}$

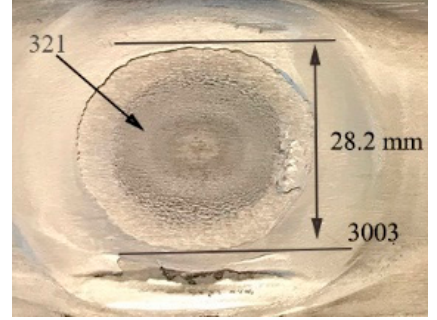

$12 \mathrm{~kJ}$

Figure 6. Lap-shear tested samples failed area at $6 \mathrm{~kJ}, 8 \mathrm{~kJ}, 10 \mathrm{~kJ}$, and $12 \mathrm{~kJ}$ input energies.

\subsection{Interfacial Morphologies}

The interface between 3003 and 5A06 is dominated by a wave-like bond, whereas AA3003 and SS321 are bonded with IMC possibly caused by element diffusion and mixing. The wavy-bonding regions with the input energy of $6,8,10$, and $12 \mathrm{~kJ}$ are shown in the red frame of Figure 7 . A symmetrically distributed wavy-bonding region is formed at the $\mathrm{Al}-\mathrm{Al}$ interface area at approximately $5 \mathrm{~mm}$ from the central area. The metals of the interlayer and the flyer plate are embedded with each other, the crest height gradually increases from the center to the sides, and the distance between the wavy bonding region and the center decreases with increasing energy. When the input energy increases, the tendency of the crest tilting towards the center increases.

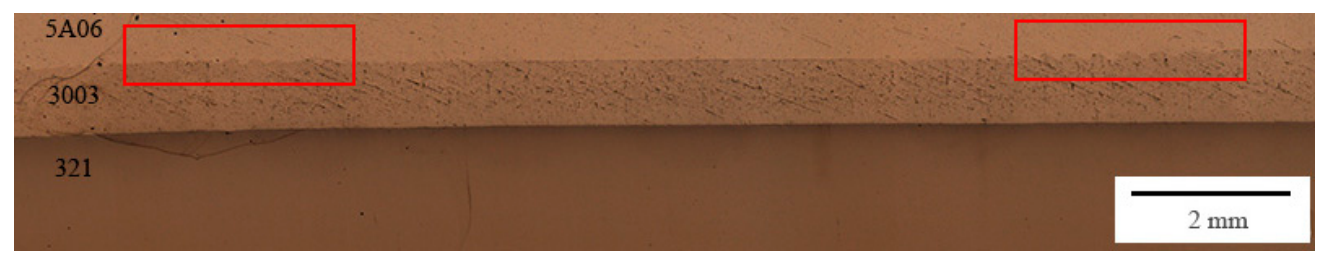

$6 \mathrm{~kJ}$

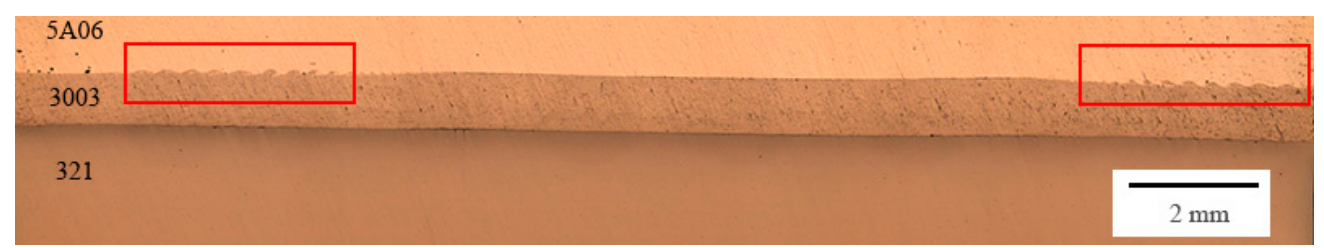

$8 \mathrm{~kJ}$

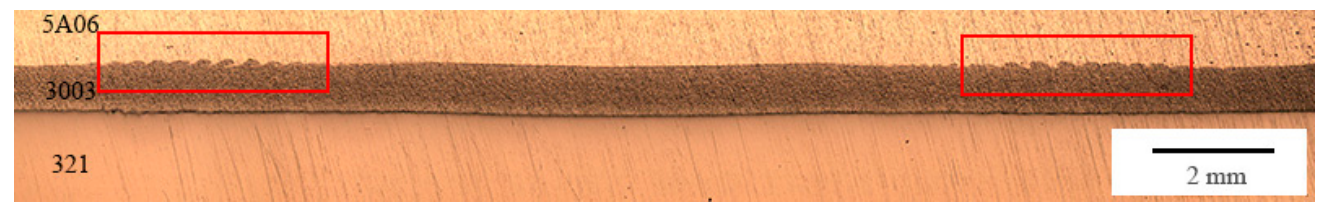

$10 \mathrm{~kJ}$

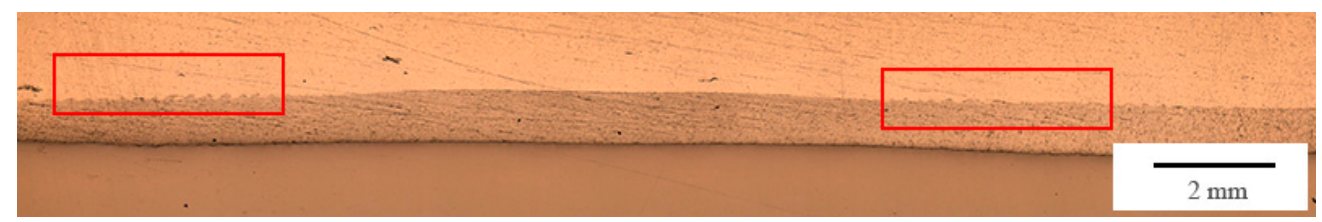

$12 \mathrm{~kJ}$

Figure 7. Interface morphologies of flyer and interlayer at $6 \mathrm{~kJ}, 8 \mathrm{~kJ}, 10 \mathrm{~kJ}$, and $12 \mathrm{~kJ}$ input energies. 
The distance between the crest height, $\lambda$, and the distance, $L$, between two waves are given in Figure 8 . The crest height and inter-wave interval increase with the input energy increase. The crest heights are 96, 116, 120, and $124 \mu \mathrm{m}$, whereas the inter-wave intervals are 332, 358, 471, and $493 \mu \mathrm{m}$.

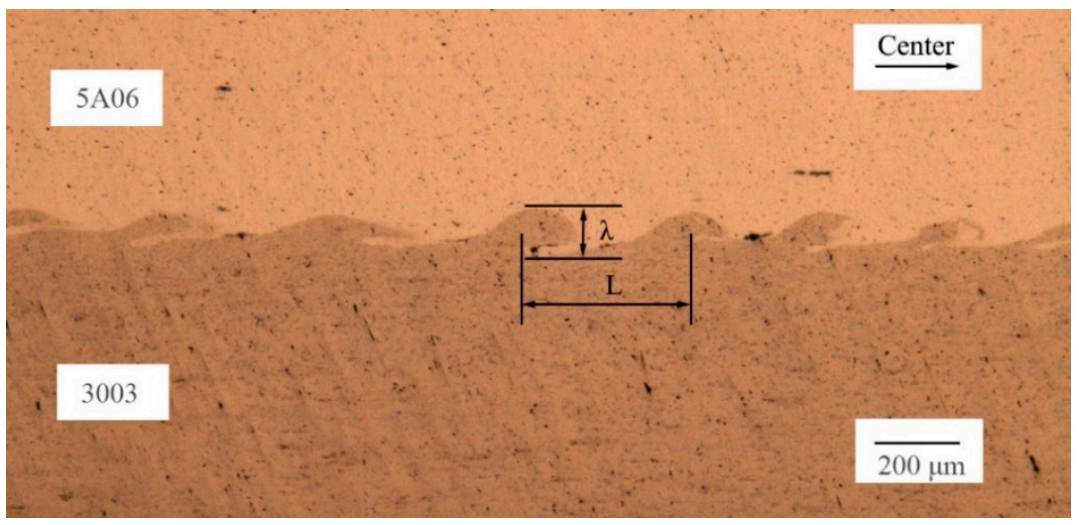

Figure 8. Interface morphologies of wave bonding area with $6 \mathrm{~kJ}$ energy input.

Figure 9 shows the distribution pattern at the interface between aluminium alloy 3003 and stainless steel 321 when the input energy is $8 \mathrm{~kJ}$. The graph shows that the bonding region at the interface between aluminium alloy 3003 and stainless steel 321 consists of the mechanical-clinch area, IMC bonding area, and an unwelded area. The unwelded area is located at the center of the joint, the mechanical-clinch zone by element diffusion is outside the IMC bonding zone, and the IMC bonding zone is flat near the aluminium alloy and irregularly undulated near the stainless steel.

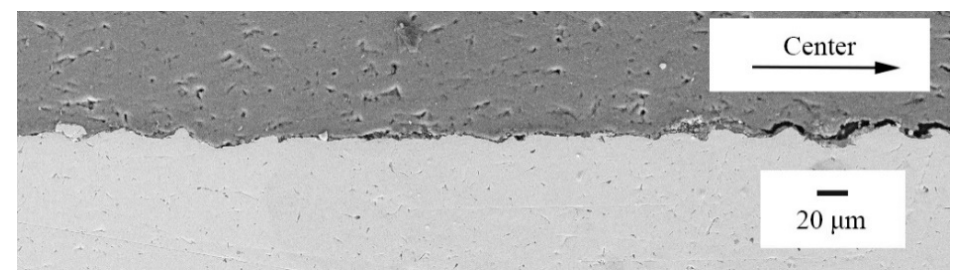

(a)

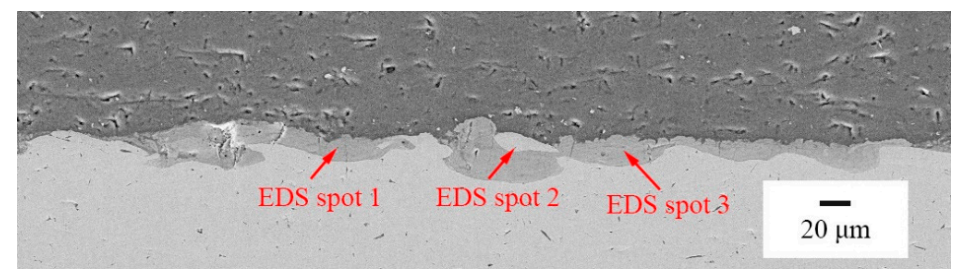

(b)

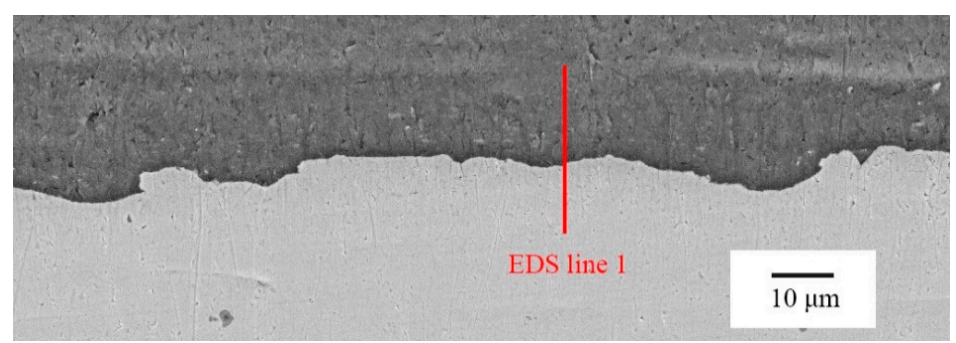

(c)

Figure 9. Interface morphologies of 3003 aluminium and 321 stainless steel at $8 \mathrm{~kJ}$ energy input. (a) unwelded area. (b) IMC bonding area. (c) Mechanical-clinch area. 
The morphologies of the IMC bonding area at energies input 6, 10, and $12 \mathrm{~kJ}$ are shown in Figure 10. The length and thickness of the IMC bonding zone at the interface increases and decreases with the input energy, respectively. When the input energy is $6 \mathrm{~kJ}$, the largest thickness of IMC at $50 \mu \mathrm{m}$ is achieved, whereas its length is approximately $300 \mu \mathrm{m}$. When the input energy increases to $10 \mathrm{~kJ}$, the thickness of the interface is reduced to $30 \mu \mathrm{m}$, and the IMC is discontinuously distributed with approximately $2 \mathrm{~mm}$ in length. The thickness of IMC reduced to $26 \mu \mathrm{m}$ with energy input increased to $12 \mathrm{~kJ}$.

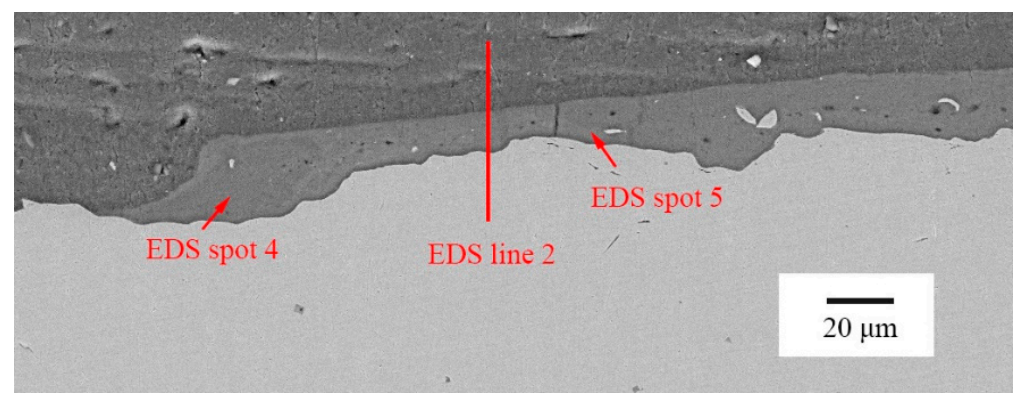

$6 \mathrm{~kJ}$

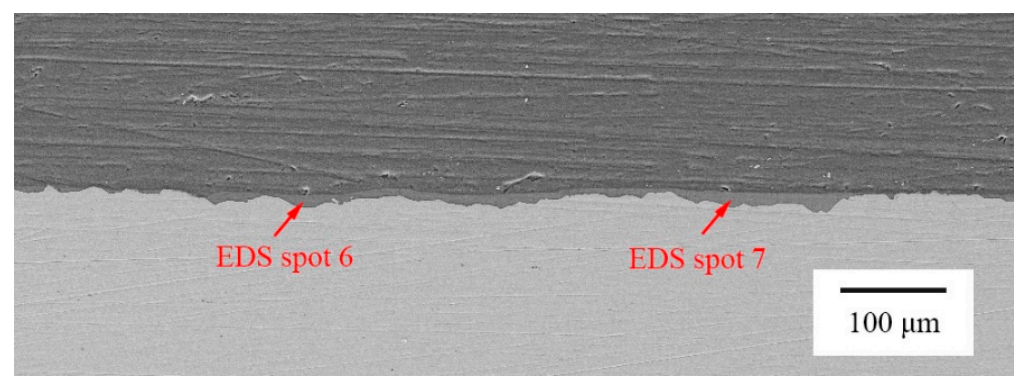

$10 \mathrm{~kJ}$

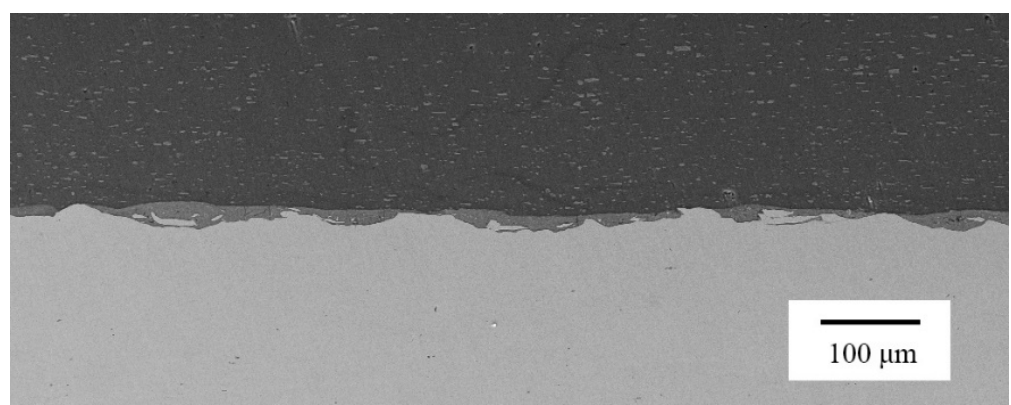

$12 \mathrm{~kJ}$

Figure 10. Interface morphologies with $6 \mathrm{~kJ}, 10 \mathrm{~kJ}$, and $12 \mathrm{~kJ}$ input energies.

The interface morphologies of the center area with $12 \mathrm{~kJ}$ energy input is shown in Figure 11. At high impact velocities and low impact angles, overheated regions were formed at the center of the interface between the interlayer and target at the input energy level of $12 \mathrm{~kJ}$ causing damage on the interlayer, and therefore the bonding strength was impaired, with the tensile load decreased to $42.6 \mathrm{kN}$. 


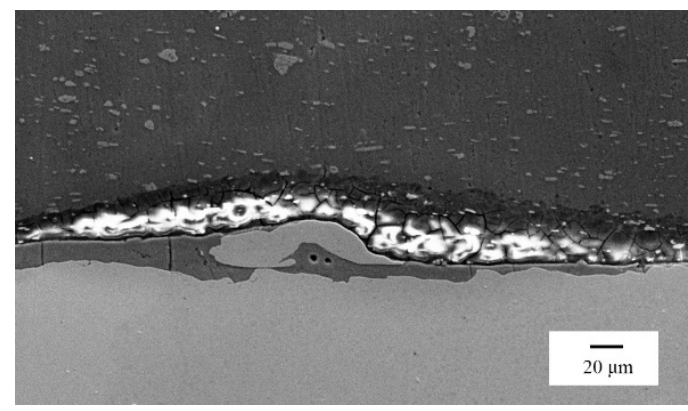

Figure 11. Interface morphologies of center area with $12 \mathrm{~kJ}$ energy input.

As shown from the failure areas of the specimens after the lap-shear and peel tests, the weld area at the interface between aluminium alloy 3003 and stainless steel 321 is significantly larger than that between aluminium alloy 3003 and aluminium alloy 5A06. The failure zone of each joint is located at the central area of the interface between aluminium alloy 3003 and stainless steel 321. In the VFAW process, which is driven by the energy of aluminium foil vaporization, the flyer plate initially collides with the interlayer. The flyer plate and interlayer then impact the target plate together, thus producing a high collision angle between the flyer plate and external side of the interlayer. This collision prevents the formation of a reliable weld. The collision angle between the interlayer and central area of the target plate increases externally, thus rendering the bonding strength of the region smaller than that of the external side.

The element line scanning results at the interface between aluminium alloy 3003 and stainless steel 321 are given in Figure 12. The welded areas at the interface between aluminium alloy 3003 and stainless steel 321 and at the central area close to the joint are mainly characterized by IMC. Within a certain distance from the center of the joint, the collision angle between the interlayer and target plate increases. At the interface, a $3 \mu \mathrm{m}$ thick bonding region is formed. The intensity is significantly larger than that in the central area. The EDS scan results of Points 1-7 are shown in Table 3. The IMCs along the interface between aluminium alloy 3003 and stainless steel 321 are $\mathrm{FeAl}$ and $\mathrm{FeAl}_{3}$.

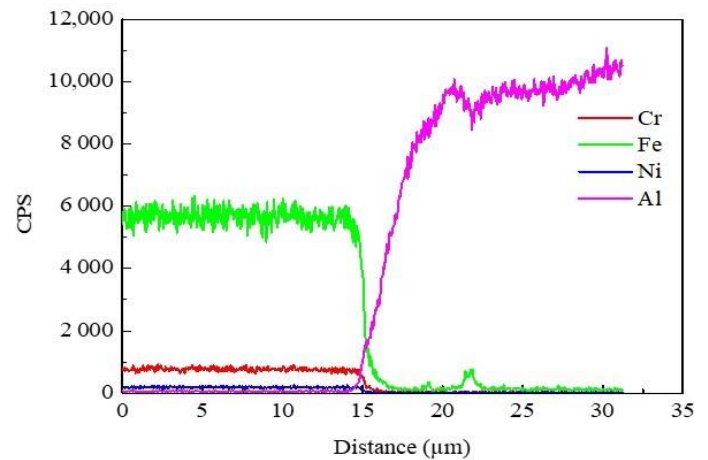

(a)

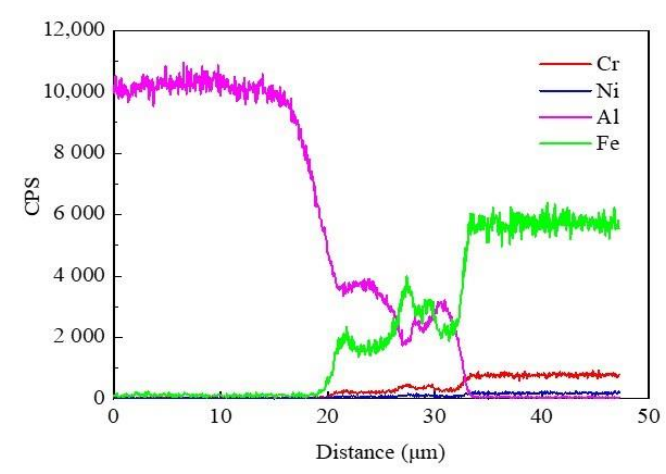

(b)

Figure 12. Element distributions of the 3003-321 interface at different areas. (a) EDS line scan of line 1; (b) EDS line scan of line 2.

Table 3. Point EDS compositional result at the interface of the interlayer and target sheet (at. \%).

\begin{tabular}{cccccccc}
\hline & EDS & EDS & EDS & EDS & EDS & EDS & EDS \\
\cline { 2 - 8 } & Spot 1 & Spot 2 & Spot 3 & Spot 4 & Spot 5 & Spot 6 & Spot7 \\
\hline $\mathrm{Al}$ & 42.3 & 0.77 & 42.49 & 62.99 & 67.16 & 66.79 & 67.17 \\
$\mathrm{Fe}$ & 42.56 & 69.79 & 42.47 & 21.61 & 22.84 & 22.54 & 22.25 \\
\hline
\end{tabular}




\section{Conclusions}

5A06 aluminium alloy and 321 stainless steel were welded by VFAW using an AA3003 interlayer and joints with good structure and properties were obtained. With input energies of $6 \mathrm{~kJ}, 8 \mathrm{~kJ}$, and $10 \mathrm{~kJ}$, the shear and tensile strengths are increased due to increased welded area. The joints with the best mechanical properties were obtained at the input energy of $10 \mathrm{~kJ}$, which had a failure load of $44 \mathrm{kN}$ in lap shear mode and $2.15 \mathrm{kN}$ in peel mode of loading. Microstructure characterization revealed a wavy pattern between the flyer and interlayer which have similar properties. The interface between the interlayer and target showed the presence of IMCs, identified as $\mathrm{Al}_{3} \mathrm{Fe}$ and $\mathrm{FeAl}$, which were continuously or intermittently distributed along the interface depending on the input energy. The results show that the use of an interlayer is a viable solution for impact welding of materials which are otherwise difficult to weld.

Author Contributions: Data curation, S.S.; Funding acquisition, S.C. and G.D.; Investigation, S.S. and A.V.; Methodology, A.V.; Project administration, S.C.; Software, J.X.; Supervision, G.D.; Writing—original draft, S.S.; Writing-review \& editing, Y.M.

Funding: This research was funded by National Nature Science Foundation of China (Grant Number 51575012). The OSU work was funded by the Department of Energy, Office of Energy Efficiency and Renewable Energy (EERE), Vehicle Technology Office under award number DE-0007813. The author gratefully acknowledges financial support from China Scholarship Council.

Conflicts of Interest: The authors declare no conflict of interest.

Disclaimer: Neither the U.S. Government, nor any of its employees, makes any warranty, express or implied, or assumes any legal liability or responsibility for the accuracy or completeness of any information, product, or process disclosed, or represents that its manufacture or use would not infringe privately owned rights. Any reference to a commercial product, process, or service does not constitute an endorsement or favoring by the U.S. Government. The views and opinions of the authors stated do not necessarily reflect those of the U. S. Government.

\section{References}

1. Sahin, M. Joining of stainless-steel and aluminium materials by friction welding. Int. J. Adv. Manuf. Technol. 2009, 41, 487-497. [CrossRef]

2. Sun, Z.; Karppi, R. The application of electron beam welding for the joining of dissimilar metals: An overview. J. Mater. Process. Technol. 1996, 59, 257-267. [CrossRef]

3. Jafarian, M.; Khodabandeh, A.; Manafi, S. Evaluation of diffusion welding of 6061 aluminum and AZ31 magnesium alloys without using an interlayer. Mater. Des. 2015, 65, 160-164. [CrossRef]

4. Zhang, W.; Sun, D.; Han, L.; Liu, D. Interfacial microstructure and mechanical property of resistance spot welded joint of high strength steel and aluminium alloy with 4047 AlSi12 interlayer. Mater. Des. 2014, 57, 186-194. [CrossRef]

5. Song, J.L.; Lin, S.B.; Yang, C.L.; Fan, C.L. Effects of Si additions on intermetallic compound layer of aluminum-steel tig welding-brazing joint. J. Alloys Compd. 2009, 488, 217-222. [CrossRef]

6. Wang, H.Y.; Zhang, Z.D.; Liu, L.M. The effect of galvanized iron interlayer on the intermetallics in the Laser weld bonding of Mg to Al fusion zone. J. Mater. Eng. Perform. 2013, 22, 351-357. [CrossRef]

7. Wang, H.; Liu, L.; Liu, F. The characterization investigation of laser-arc-adhesive hybrid welding of $\mathrm{Mg}$ to $\mathrm{Al}$ joint using Ni interlayer. Mater. Des. 2013, 50, 463-466. [CrossRef]

8. Balakrishnan, M.; Balasubramanian, V.; Madhusudhan Reddy, G. Effect of hardfaced interlayer thickness on ballistic performance of armour steel welds. Mater. Des. 2013, 44, 59-68. [CrossRef]

9. Date, H.; Kobayakawa, S.; Naka, M. Microstructure and bonding strength of impact-welded aluminium-stainless steel joints. J. Mater. Process. Technol. 1999, 85, 166-170. [CrossRef]

10. Corigliano, P.; Crupi, V.; Guglielmino, E.; Mariano Sili, A. Full-field analysis of Al/Fe explosive welded joints for shipbuilding applications. Mar. Struct. 2018, 57, 207-218. [CrossRef]

11. Corigliano, P.; Crupi, V.; Guglielmino, E. Non linear finite element simulation of explosive welded joints of dissimilar metals for shipbuilding applications. Ocean Eng. 2018, 160, 346-353. [CrossRef]

12. Topolski, K.; Szulc, Z.; Garbacz, H. Microstructure and properties of the Ti6Al4V/Inconel 625 bimetal obtained by explosive joining. J. Mater. Eng. Perform. 2016, 25, 3231-3237. [CrossRef] 
13. Findik, F. Recent developments in explosive welding. Mater. Des. 2011, 32, 1081-1093. [CrossRef]

14. Xie, M.; Shang, X.; Zhang, L.; Bai, Q.; Xu, T. Interface characteristic of explosive-welded and hot-rolled Ta1/X65 bimetallic plate. Metals 2018, 8, 159. [CrossRef]

15. Kaya, Y. Microstructural, mechanical and corrosion investigations of ship steel-aluminum bimetal composites produced by explosive welding. Metals 2018, 8, 544. [CrossRef]

16. Balasundaram, R.; Patel, V.K.; Bhole, S.D.; Chen, D.L. Effect of zinc interlayer on ultrasonic spot welded aluminum-to-copper joints. Mater. Sci. Eng. A 2014, 607, 277-286. [CrossRef]

17. Berlin, A.; Nguyen, T.C.; Worswick, M.J.; Zhou, Y. Metallurgical analysis of magnetic pulse welds of AZ31 magnesium alloy. Sci. Technol. Weld. Join. 2013, 16, 728-734. [CrossRef]

18. Zhang, Y.; Babu, S.S.; Prothe, C.; Blakely, M.; Kwasegroch, J.; LaHa, M.; Daehn, G.S. Application of high velocity impact welding at varied different length scales. J. Mater. Process. Technol. 2011, 211, 944-952. [CrossRef]

19. Yılmaz, M.; Çöl, M.; Acet, M. Interface properties of aluminum/steel friction-welded components. Mater. Charact. 2002, 49, 421-429. [CrossRef]

20. Madhusudhan Reddy, G.; Venkata Ramana, P. Role of nickel as an interlayer in dissimilar metal friction welding of maraging steel to low alloy steel. J. Mater. Process. Technol. 2012, 212, 66-77. [CrossRef]

21. Han, J.H.; Ahn, J.P.; Shin, M.C. Effect of interlayer thickness on shear deformation behavior of AA5083 aluminum alloy/SS41 steel plates manufactured by explosive welding. J. Mater. Sci. 2003, 38, 13-18. [CrossRef]

22. Manikandan, P.; Hokamoto, K.; Fujita, M.; Raghukandan, K.; Tomoshige, R. Control of energetic conditions by employing interlayer of different thickness for explosive welding of titanium/304 stainless steel. J. Mater. Process. Technol. 2008, 195, 232-240. [CrossRef]

23. Vivek, A.; Hansen, S.R.; Liu, B.C.; Daehn, G. Vaporizing foil actuator: A tool for collision welding. J. Mater. Process. Technol. 2013, 213, 2304-2311. [CrossRef]

24. Vivek, A.; Hansen, S.; Benzing, J.; He, M.; Daehn, G. Impact welding of aluminum to copper and stainless steel by vaporizing foil actuator: Effect of heat treatment cycles on mechanical properties and microstructure. Metall. Mater. Trans. A 2015, 46, 4548-4558. [CrossRef]

25. Liu, B.; Vivek, A.; Presley, M.; Daehn, G. Dissimilar impact welding of 6111-T4, 5052-H32 aluminum alloys to 22MnB5, Dp980 steels and the structure-property relationship of a strongly bonded interface. Metall. Mater. Trans. A 2018, 49, 899-907. [CrossRef]

26. Liu, B.; Vivek, A.; Daehn, G.S. Joining sheet aluminum AA6061-T4 to cast magnesium AM60B by vaporizing foil actuator welding: Input energy, interface, and strength. J. Manuf. Process. 2017, 30, 75-82. [CrossRef]

27. Nassiri, A.; Zhang, S.; Lee, T.; Abke, T.; Vivek, A.; Kinsey, B.; Daehn, G. Numerical investigation of Cp-Ti \& Cu110 impact welding using smoothed particle hydrodynamics and arbitrary lagrangian-eulerian methods. J. Manuf. Process. 2017, 28, 558-564.

28. Chen, S.; Huo, X.; Guo, C.; Wei, X.; Huang, J.; Yang, J.; Lin, S. Interfacial characteristics of Ti/Al joint by vaporizing foil actuator welding. J. Mater. Process. Technol. 2019, 263, 73-81. [CrossRef]

29. Johnson, J.R.; Taber, G.; Vivek, A.; Zhang, Y.; Golowin, S.; Banik, K.; Fenton, G.K.; Daehn, G. Coupling experiment and simulation in electromagnetic forming using photon doppler velocimetry. Metal Form. 2009, 80, 359-365.

30. Vivek, A.; Hansen, S.R.; Daehn, G. High strain rate metalworking with vaporizing foil actuator: Control of flyer velocity by varying input energy and foil thickness. Rev. Sci. Instrum. 2014, 85, 75101. [CrossRef] [PubMed]

(C) 2019 by the authors. Licensee MDPI, Basel, Switzerland. This article is an open access article distributed under the terms and conditions of the Creative Commons Attribution (CC BY) license (http://creativecommons.org/licenses/by/4.0/). 